\title{
Anti-Inflammatory Activity of Quantum Energy Living Body on Lipopolysaccharide-Induced Murine RAW 264.7 Macrophage Cell Line
} Jong Doo Lee ${ }^{1}$, Emil Joseph S Vergara ${ }^{2}$, Soo Hee $\mathrm{Choi}^{2}$, Seong Gu Hwang ${ }^{2 *}$ and Gun Woong Bahng ${ }^{3}$

${ }^{1}$ Quantum Energy Research Center, An-Yang, Kyung Ki Do, 431-804, Republic of Korea

${ }^{2}$ Department of Animal Life and Environmental Science, Hankyong National University, Korea

${ }^{3}$ Qelby Research Institute, The State University of New York, Korea, Incheon, 21985, Korea

\begin{abstract}
Recent developments from science and medical science show a growing interest in the anti-inflammatory activity of natural materials. Inflammation is the body's physiologic response to injurious stimulation and is known to be mediated by various pro-inflammatory cytokines (e.g. TNF- $\alpha, \mathrm{IL}-1 \beta, \mathrm{IL}-6$ etc) and iNOS (inducible nitric oxide synthase). Quantum energy living body (QELBY) powder is a fusion of a special ceramic powder with natural clay mineral classified as quantum energy radiating material (QERM). The powder, composed mostly of silicon dioxide, is known to radiate reductive radiant energy. This study was designed to evaluate the anti-inflammatory activities of QELBY powder on RAW 264.7 mouse macrophage cells. QELBY powder was mixed with DMEM media and was allowed to stand for 48 hours. Afterwards, the supernatant was taken and diluted to various concentrations $(0,5,10,20,40 \mu \mathrm{g} / \mathrm{ml})$ prior to use. CCK-8 assay was done to determine the effects on cell viability. In addition, NO assay performed to elucidate the effect of QELBY on the NO production of LPS-stimulated macrophages. Lastly, RT-PCR and Western blot analysis for the detection of the mRNA and protein expressions, respectively, of proinflammatory cytokines and iNOS was made. Results demonstrated that QELBY powder causes both an increase in cell proliferation and a concentration-dependent decrease in NO production. Moreover, the mRNA and protein expressions of pro-inflammatory cytokines and iNOS were also inhibited. Taken together, these show that QELBY powder has anti-inflammatory activity and could therefore be used further in the development of materials that induce such kinds of benefits.
\end{abstract}

Keywords: Quantum energy radiating material (QERM); Quantum energy living body (QELBY); Quantum energy; RAW 264.7 murine macrophage cell line; Anti-inflammation

\section{Introduction}

Quantum energy living body (QELBY) powder is a fusion of a special ceramic powder with natural clay mineral classified as quantum energy radiating material (QERM). The powder, composed mostly of silicon dioxide, is stable in temperatures as high as $1000^{\circ} \mathrm{C}$ and is known to radiate reductive radiant energy [1]. Several tests have already been done to assess the effect of QERM. QERM is starting to be applied in different fields including improvements in the biologic processes of plants and animals. It has been shown that it has antioxidant, antibacterial, immune enhancing and anticancer properties. Aside from the aforementioned biological effects, it has also been shown to absorb electromagnetic waves, prevent corrosion and neutralize toxicity. QERM is said to exert its biological functions through the emission of reductive radiant energy which is said to activate both plant and animal cells. This kind of energy is said to be able to penetrate glass, chemicals and even the human body making the structure of water molecules hexagonal in shape. In addition, reductive radiant energy also generates negative electrons which allows for the exertion of its antioxidant, immune enhancing and cancer suppressing properties. Inflammation is the primary and physiologic response of the immune system to injury which is aimed at removing pathological noxae and restoring homeostasis $[2,3]$. The 5 hallmarks of inflammation are redness, swelling, heat, pain and loss of function. The descriptions are due to an increase in the blood flow into the site of injury due to the release of so-called inflammatory mediators (eicosanoids and cytokines) by the sentinel cells (e.g. dendritic cells). Inflammation has garnered tremendous amount of attention due to established links with several pathologies including cancer, metabolic and degenerative diseases [3-6]. Macrophages are classified under the mononuclear phagocytes of the immune system. These cells are derived from blood monocytes, which originated from bone marrow precursor cells. Macrophages are important in innate immunity for they serve as Sentinel cells that have vital functions in pathogen clearance and, more importantly, antigen presentation. Macrophages are known to be able to phagocytose a wide variety of pathogens through countless years of evolution. This function is due to the presence of pattern recognizing receptors (PRRs), which serve as receptors for a wide array of pathogenic organisms', mostly bacterial, conserved surface antigens [7]. The monocytes-macrophage system exists in at least two distinct phenotypes: classical/pro-inflammatory (M1) and alternative/antiinflammatory (M2) [8]. The activated state of each distinct phenotype largely depends on the variety of cytokines and microbial products that switch on distinct transcription networks $[9,10]$. Upon inflammatory stimuli, such as lipopolysaccharide, marcrophages are triggered to produce and release a diverse set of inflammatory mediators such as tumor necrosis factor- $\alpha$ (TNF- $\alpha$ ), interleukin-1, interferons, prostaglandins and nitric oxide (NO) [11,12]. These so-called mediators are part of the host defense system against the potential etiologic agent or cause of injury. However, excessive production of these inflammatory products, for instance TNF- $\alpha$ and NO, could

*Corresponding author: Seong Gu Hwang, Department of Animal Life and Environmental Science, Hankyong National University, Korea, Tel: +82-10-32133808; Fax: +82-31-670-5121; E-mail: sghwang@hknu.ac.kr

Received November 20, 2015; Accepted January 14, 2016; Published January 25, 2016

Citation: Lee JD, Vergara EJS, Choi SH, Hwang SG, Bahng GW (2016) AntiInflammatory Activity of Quantum Energy Living Body on LipopolysaccharideInduced Murine RAW 264.7 Macrophage Cell Line. Bioceram Dev Appl 6: 089. doi:10.4172/2090-5025.100089

Copyright: (C) 2016 Lee JD, et al. This is an open-access article distributed unde the terms of the Creative Commons Attribution License, which permits unrestricted use, distribution, and reproduction in any medium, provided the original author and source are credited. 
lead to pathologic consequences [13,14]. The aim of the study was to determine the effect of direct exposure with QELBY powder to the inflammation-related changes in LPS-induced RAW 264.7 murine macrophage cells.

\section{Materials and Methods}

\section{Preparation of treatment stock from QELBY powder}

QELBY powder was bought from Quantum Energy ${ }^{\circledR}$ and was sterilized by autoclaving. $0.3 \mathrm{~g}$ of QELBY powder was mixed with 30 ml DMEM with $10 \%$ FBS and $1 \%$ penicilin-streptomycin $(\mathrm{P} / \mathrm{S})$ for 24 hours. After soaking, the supernatant was filtered with Whatman Filter paper and the weight of the filtered powder obtained in order to compute for the total dissolved QELBY powder in the media. The stock solution was then diluted to certain concentrations $(5,10,20,40 \mu \mathrm{g} / \mathrm{ml})$ prior to use.

\section{Cell line and cell culture}

Murine RAW 264.7 was obtained from the Korean Cell line Bank (KCLB, Korea) and were cultured in Dulbeco's Modified Eagle's Medium (DMEM) $\left(\right.$ Gibco $^{\circledR}$, USA) supplemented with $10 \%$ heat inactivated fetal bovine serum (FBS) (Gibco ${ }^{\circledR}$, USA) and Penicillin/ Streptomycin $\left(100 \mathrm{U} / \mathrm{mL}\right.$ ) (Lonza, USA) and $3.7 \mathrm{mg} / \mathrm{mL}$ of $\mathrm{NaHCO}_{3}$ at $37^{\circ} \mathrm{C}$ in $5 \% \mathrm{CO}_{2}$.

\section{Cell viability analysis}

Cell counting kit-8 (CCK-8, Dojindo, Japan) was used to quantify viability of RAW 264.7 macrophage cells according to the manufacturer's instruction. Seeding at a density of $10^{4}$ cells per well was done and were incubated in DMEM at $37^{\circ} \mathrm{C}$ in $5 \% \mathrm{CO}_{2}$ for 24 hours. The cells were then pretreated with LPS $(10 \mu \mathrm{g} / \mathrm{mL})$. After 2 hours, treatment with media with increasing concentrations of dissolved QELBY was performed. After 24 hours of incubation, media in the wells were suctioned and $100 \mu \mathrm{L}$ of fresh media with $10 \mu \mathrm{L}$ CCK-8 was added per well which was incubated at $37^{\circ} \mathrm{C}$ for 2 hours. Absorbance at 450 nm was measured using an ELISA plate reader (TECAN, Switzerland). Viability of the treated cells was expressed as the percentage of control cells

\section{NO assay}

Total NO produced by Lipopolysaccharide (LPS) (Sigma ${ }^{\circledR}$, USA) stimulated RAW 264.7 macrophage cells was determined with the use of Griess reagent. $5 \times 10^{4}$ cells seeded per well were incubated for 24 hours. Pretreatment with LPS $(10 \mu \mathrm{g} / \mathrm{mL})$ was done prior to treatment with increasing concentrations of media with QELBY. After 24 hours of incubation, $50 \mu \mathrm{L}$ of the media collected from each well was transferred to a new well with an equal volume of Griess reagent (5\% phosphoric acid (99.9\%), 2\% sulfacilamide (99.9\%), 2\% N-(1Naphthyl) ethylenediamine dihydrochloride (98\%)). The plate was covered in foil and incubated for 15 minutes. Absorbance at $540 \mathrm{~nm}$ was measured using an ELISA plate reader. The total NO content of each well was obtained by the formula below.

\section{NO content $=$ OD570 reading $/ 0.0049$}

\section{RT-PCR}

Total RNA was obtained from LPS and QELBY treated RAW 264.7 cells using Trizol reagent (Takara, Korea) according to the manufacturer's instructions. $1 \mu \mathrm{g}$ of RNA was used to acquire the complementary DNA (cDNA) using the protocol provided by $\mathrm{M}-\mathrm{MuLV}$ reverse transcriptase (Fermentas, Lithuania). Specific primers were used to amplify different genes. PCR products were then separated by electrophoresis using $1.5 \%$ agarose stained with ethidium bromide and UV transillumination was done afterwards. PCR analysis was done three times and the densitometry analysis carried out using Lane 1-D ${ }^{\circledR}$ software.

\section{Western blot analysis}

The isolation and determination of protein concentration was carried out using Bradford assay. Cells that had undergone treatment for 24 hours were lysed using a protein extraction solution (Intron Biotechnology, Korea) and the protein concentration was determined using the Bio-Rad protein assay (Bio-Rad Laboratories, USA). $30 \mu \mathrm{g}$ of the extracted protein was separated in 10\% SDS-PAGE. Afterwards it was transferred to a nitrocellulose membrane (Schleicher and Schuell, Germany) and blocked for 2 hours with 5\% skim milk in TBST buffer (20 mM Tris- $\mathrm{HCl}, \mathrm{pH} 7.6,140 \mathrm{mM} \mathrm{NaCl}, 0.1 \%$ Tween 20). The membrane was washed four times with TBST and incubated overight in $2 \%$ skim milk containing the primary antibodies (monoclonal antiTNF $\alpha$, anti-iNOS, anti-NF-KB, anti-IL- $1 \beta$. anti-IL-4 and anti-IL-6) at a 1:1000 dilution. Washing with TBST buffer was done for four times then the membranes were incubated with horse radish peroxidaselabeled secondary antibody (Santa Cruz Biotechnology, USA) diluted to 1:2000 for another 2 hours. Lastly, the membranes were washed four times with TBST buffer and detection of bands was done with the use of the enhanced chemiluminesence system (ECL, Western Blot Analysis System Kit, Amersham Biosciences, Korea). The experiment was carried out three times and the resulting blot was quantified using densitometry analysis with Lane $1-\mathrm{D}^{\circledR}$ software.

\section{Statistical analysis}

All experiments were done in triplicates and data were expressed as means \pm SD. The difference between control and treated cells were evaluated using one-way ANOVA followed by Duncan Multiple Range Test. P values less than 0.05 were considered statistically significant.

\section{Results}

\section{Cell viability analysis}

CCK- 8 assay is a widely-used method to quantify cells to determine a compound's mitogenic or toxic properties to cells. Cell viability analysis has shown a dose-dependent increase in the quantity of LPSstimulated cells after direct treatment with QELBY powder for 24 hours. It can be seen in Figure 1 that even at very low concentrations of the said mineral, a statistically significant increase in the proliferation of the RAW 264.7 macrophage cells occurs with as much as $43.95 \%$ increase in the quantity of cells at $40 \mu \mathrm{g} / \mathrm{mL}$ of exposure $(\mathrm{p}<0.05)$. This data also shows that QELBY powder has no cytotoxic effects with respect to the concentrations used in this study Figure 1.

\section{NO assay}

NO determination by Griess reaction has shown a statistically significant decrease $(p<0.05)$ in the NO production by the LPS-induced RAW 264.7 macrophage cells after treatment with QELBY powder for 24 hours. Similar to the cell viability assay, a dose-dependent effect was observed even after treatment with a small concentration of the powder with as much as $10.87 \%, 15.0 \%, 22.83 \%$ and $31.85 \%$ inhibition for 5,10 , 20 and $40 \mu \mathrm{g} / \mathrm{mL}$ respectively Figure 2 .

\section{RT-PCR analysis}

Exposure of the macrophage cells used in the study showed a dose- 


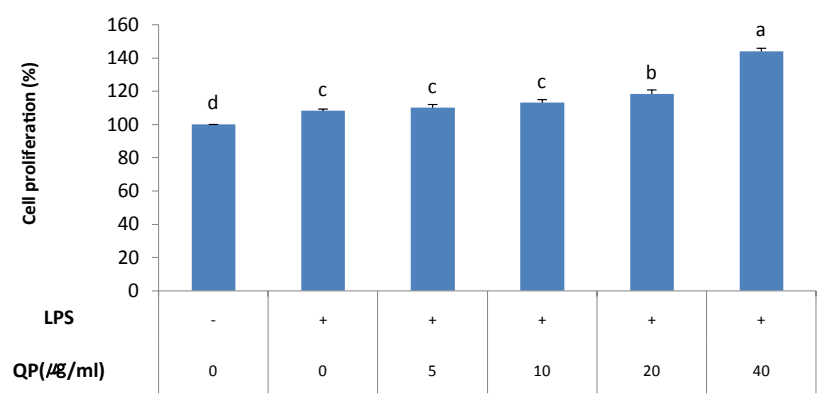

Figure 1: Effect of treatment with QELBY powder (QP) on the viability of murine LPS-induced RAW 264.7 macrophage cells after incubation for 24 hours. Data are means \pm SEM $(n=4)$. Means with different superscripts are significantly different at $p<0.05$.

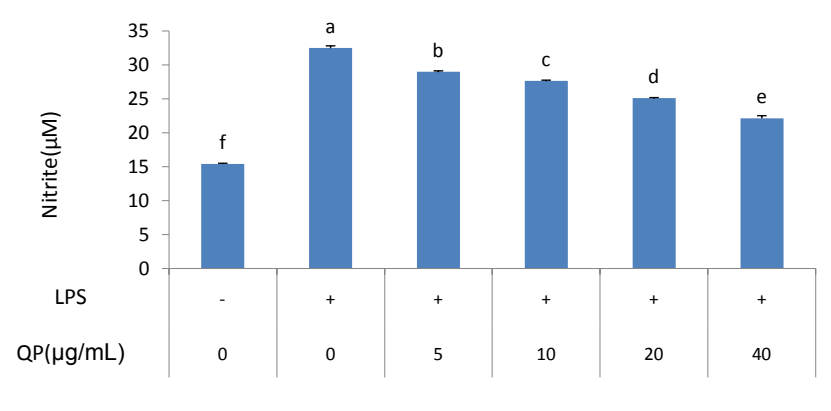

Concentration of QELBY Textile powder $(\mu \mathrm{g} / \mathrm{ml})$

Figure 2: Effect of treatment with QELBY powder (QP) on the NO production of LPS-stimulated murine RAW 264.7 macrophage cells after incubation for 24 hours. Data are means \pm SEM $(n=4)$. Means with different superscripts are significantly different at $p<0.05$. dependent decrease in the mRNA expression of all inflammationrelated genes using RT-PCR assay. Marked decrease in the band intensities was seen for NF- $\kappa \mathrm{B}$, TNFa, IL-4 and iNOS with increasing concentration of QELBY powder while a partial decrease was seen in IL- $1 \beta$ and IL- 6 as shown in Figure 3.

\section{Western blot analysis}

Similar to the results seen in RT-PCR, exposure of the LPSstimulated macrophages to QELBY powder resulted in decreased protein expression of the molecules for the study. A decrease in the protein expression of TNF- $\alpha$, iNOS, IL- $1 \beta$, NF- $\kappa B$, IL- 4 and IL- 6 was shown by Western blotting with $\beta$-actin serving as the house-keeping protein. The densitometry analysis shows a more detailed view of the results of obtained Figure 4.

\section{Discussion}

Macrophages are essential cells of the innate immune system due to their diverse functions and integral roles in pathogen clearance and inflammatory processes [7]. Cell viability analysis has shown that exposure to QELBY causes an increase in the quantity of cells even at low concentrations. An increase in the number of macrophages may be of importance since an increased quantity of these cells can be directly correlated to an increased capability of the innate immune system for pathogen clearance. Moreover, several studies [15-18] have already shown that macrophages are also beneficial in tissue homeostasis, tissue repair and cell proliferation after injury. Inflammation is a physiologic response to the presence of injurious stimuli in an animal's body. However, excessive inflammation leads to the development of several pathologies. Inflammation is already known to be involved in many important pathological processes of several diseases. This is due to the toxic effects of several inflammatory mediators produced by cells at the site of inflammation $[19,20]$. Several researches have already strongly

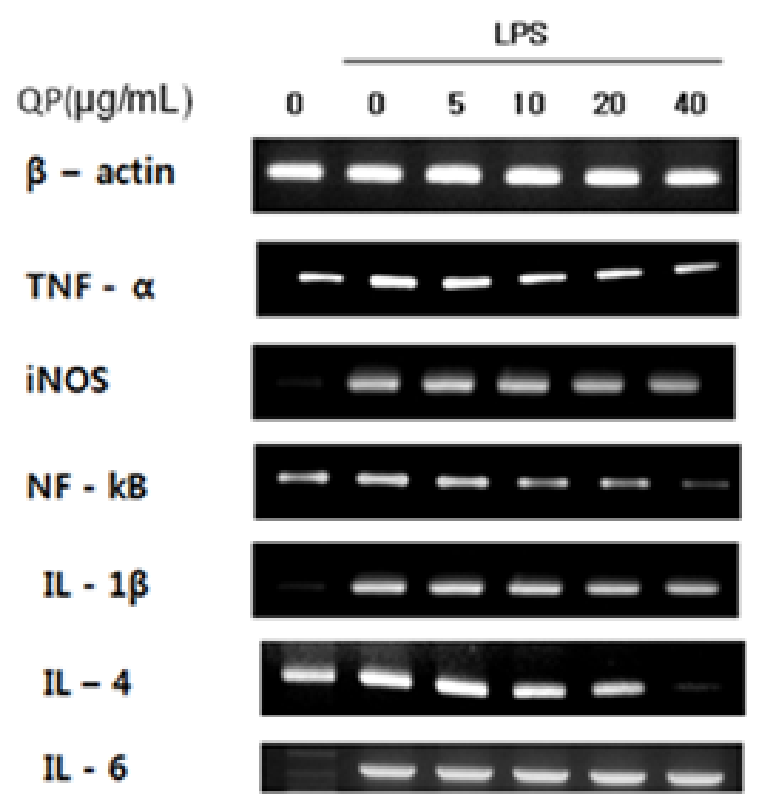

A
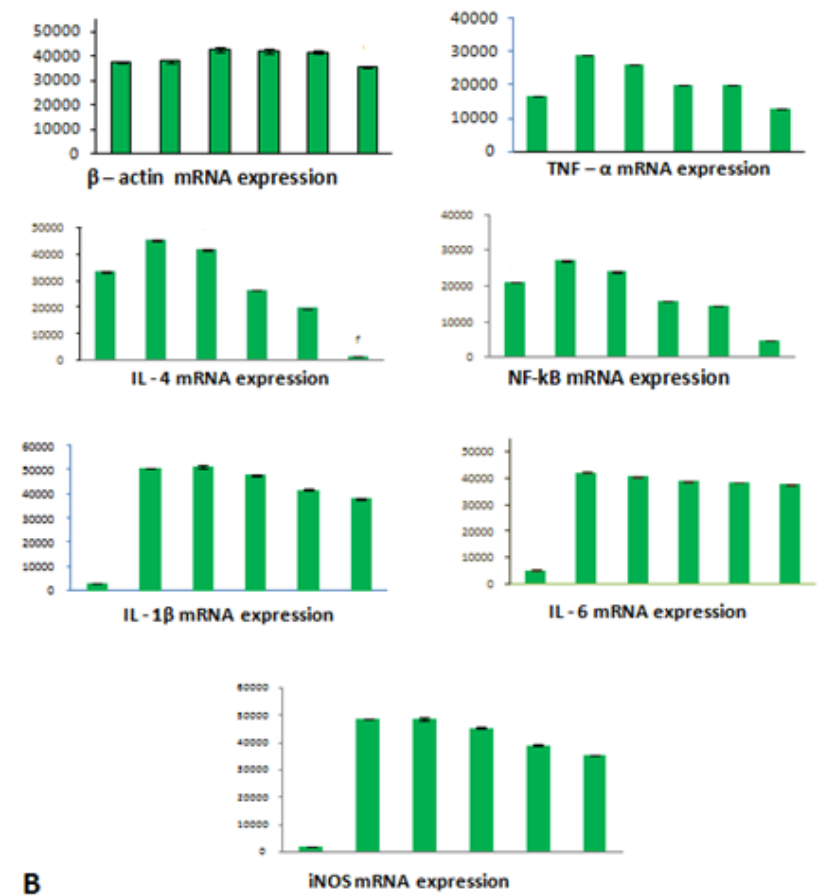

Figure 3: The effect of treatment with QELBY powder (QP) on the mRNA expression of inflammation-related genes in RAW 264.7 murine macrophage cells stimulated with LPS. The PCR products after electrophoresis (A) and the graphs showing the comparative densities of the bands $(B)$ are shown ( $n=3)$. 


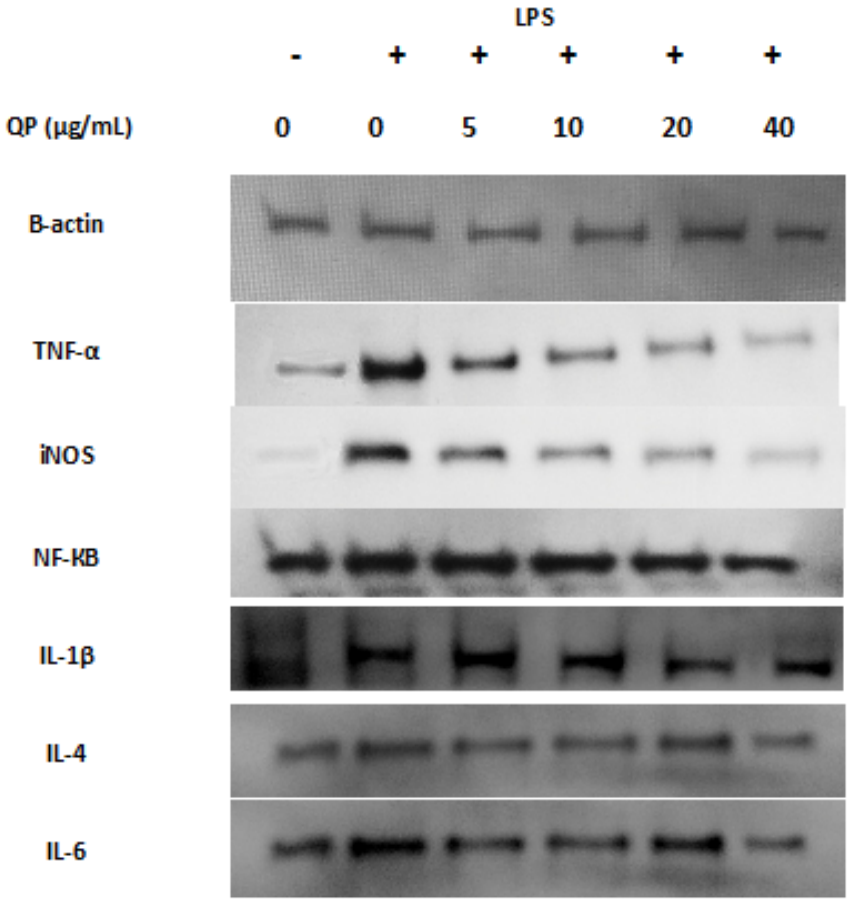

A
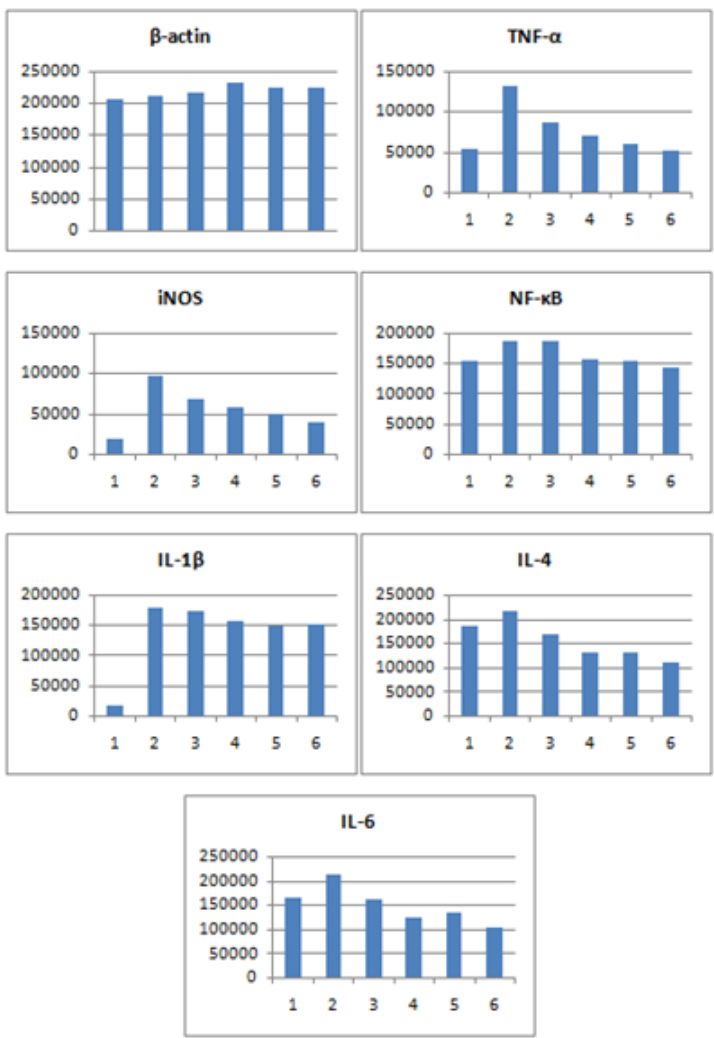

B

Figure 4: Effect of treatment with QELBY powder (QP) on the protein expression of inflammation-related genes in murine RAW 264.7 macrophage cells. The relative protein expression $(A)$ and the quantitative protein expression obtained through densitometry analysis $(B)$ are shown.

emphasized and have shown compelling evidence on the importance of blocking inflammation for the prevention of many disease states both in animals and humans [19,21-23]. Results of the study have shown that exposure of RAW 264.7 murine macrophage cells, a prototype cell line for studies on inflammation, leads to a decrease in the inflammatory response through the decrease in the production of NO as well as other important pro-inflammatory products such as cytokines. Nitric oxide, a gaseous substance acting as a signaling molecule, is produced in large amounts from the amino acid L-arginine by the enzyme inducible nitric oxide synthase (iNOS) [24]. Many inflammatory cells, most especially macrophages, express iNOS upon stimulation with bacterial LPS, viruses or even other cytokines [11]. Nitric oxide exerts its effect in host defense owing to its antibacterial and virustatic properties. However, excessive production of NO could lead to detrimental effects due to its cytotoxic potential on normal host cells [11]. Results of the study have shown that exposure of the cells to QELBY caused a marked decrease in the NO produced by the LPS-stimulated cells as well as in the mRNA and protein expression of iNOS. This data shows that even at low concentrations of QELBY powder, a significant anti-inflammatory effect through the inhibition of NO production was achieved. Tumor necrosis alpha (TNF- $\alpha$ ) and interleukin 1 beta (IL-1 $\beta$ ) represent the archetypal pro-inflammatory cytokines rapidly released after the occurrence of tissue injury or infection [25]. TNF is mainly produced by macrophages and plays a major role as a pro-inflammatory mediator [26]. It is known as a central regulator of inflammation and antagonists could be effective in the prevention of inflammatory conditions or in the treatment of inflammatory disorders in which TNF- $\alpha$ plays a significant role $[27,28]$. The interleukins comprise a group of molecules involved in the signaling between the cells of the immune system. Similar to tumor necrosis factor-alpha, some interleukins, most notably interleukin 1 secreted by monocytes/macrophages, are known to cause pathologic disturbances when produced excessively and continuously [29-31]. Our experiment has shown that a decrease in the pro-inflammatory interleukins (IL-1 $\beta$, IL-4 and IL6) as well as TNF- $\alpha$ dose-dependently. The decrease in the expression, both mRNA and protein, of the aforementioned cytokines entails an antiinflammatory role of QELBY powder beyond just the suppression of NO production. Nuclear factor-kappa B (NF-KB) has long been considered as a prototypical pro-inflammatory signaling pathway. This pathway is activated upon stimulation of pro-inflammatory cytokines such as IL-1 and TNF- $\alpha$. This transcription factor is known to play a role in the expression of pro-inflammatory genes including cytokines, chemokine's and adhesion molecules [25,32]. Several chronic diseases have already been associated with NF-KB activation some of which includes asthma, inflammatory bowel disease, multiple sclerosis, rheumatoid arthritis and several cancers $[4,25,33]$. It is for these, and several more compelling reasons, that NF-KB is considered the "holy grail" as a target for inflammatory suppressive agents. RT-PCR and Western blot analysis of cells treated with the powder resulted in a significant decrease in the expression of NF-KB. This result proves to be of immense significance for it provides strong evidence for the anti-inflammatory properties of QELBY powder even at very low 
Citation: Lee JD, Vergara EJS, Choi SH, Hwang SG, Bahng GW (2016)Anti-Inflammatory Activity of Quantum Energy Living Body on LipopolysaccharideInduced Murine RAW 264.7 Macrophage Cell Line. Bioceram Dev Appl 6: 089. doi:10.4172/2090-5025.100089

concentrations $(40 \mu \mathrm{g} / \mathrm{mL})$. These results could also serve as a basis for a decrease in other inflammatory mediators not used in the study for the role NF-KB plays as a pro-inflammatory transcription factor.

\section{Conclusion}

Results of the study have demonstrated that QELBY powder have anti-inflammatory properties through the suppression of proinflammatory mediators such as iNOS, TNF- $\alpha$, IL-1 $\beta$, IL-4, and IL-6. In addition, it also causes a decrease in the expression of the master transcption factor of inflammation NF-KB. Taken together, these results show that QELBY Powder could therefore be used further in the development of materials which could be used for anti-inflammation.

\section{References}

1. Lee JD, Kulkarni A, Kim T, Bahang GW, Moh SJ, et al. (2014) Electrical Properties of "Quantum Energy ${ }^{\circledR}$ Radiating Material" Produced from Natural Clay Minerals of South Korea. Materials Focus 3: 1-5.

2. Majno G, Joris A (2004) Cells, Tissues and Diseases: Principles of General Pathology. Oxford University Press, USA.

3. Lu H, Ouyang W, Huwang C (2006) Inflammation, a Key Event in Cancer Development. Molecular Cancer Research 4: 221-233.

4. Postler TS, Ghosh S (2015) Bridging the gap: A regulator of NF-KB linking inflammation and cancer. Journal of Oral Biosciences 57: 143-147.

5. Grivennikov SI, Greten FR, Karin M (2010) Immunity, Inflammation, and Cancer. Cell 140: 883-889.

6. Nallasamy P, Si H, Babu PVA, Pan D, Fu Y, et al. (2014) Sulforaphane reduces vascular inflammation in mice and prevents TNF-a-induced monocytes adhesion to primary endothelial cells through interfering with the NF-KB pathway. Journal of Nutritional Biochemistry 25: 824-833.

7. Male D, Brostoff J, Roth DB, Roitt I (2006) Immunology. Elsevier Canada.

8. Italiani P, Boraschi D (2014) From Monocytes to M1/M2 Macrophages: Phenotypical vs. Functional Differentiation. Frontiers in Immunology.

9. Beyer M, Mallman MR, Xue J, Saratschek-Jox A, Vorholt D, et al. (2012) HighResolution Transcriptome of Human Macrophages.

10. Tugal D, Liao X, Jain MK (2013) Transcriptional control of macrophage polarization. Aterioscler Thromb Vasc Biol 33:1135-1144.

11. Kiemer AK, Muller C, Vollmar AM (2002) Inhibition of LPS-induced nitric oxide and TNF- $\alpha$ production by $\alpha$-lipoic acid in rat Kupffer cells and in RAW 264.7 murine macrophage. Immunology and Cell Biology 80: 550-557.

12. Pfeiffer K (2003) Biological functions of tumor necrosis factor cytokines and their receptors. Cytokine Growth Factor Reviews 14: 185-191.

13. Sass G, Koerber K, Bang R, Guehring H, Tiegs G (2001) Inducible nitric oxide synthase is critical for immune-mediated liver injury in mice. J Clin Invest 107: 439-447.

14. Ring A, Stremmel W (2000) The hepatic microvascular responses to sepsis. Semin Thromb Hemost 26: 589-594.

15. Divangahi M, King IL, Pernet E (2015) Alveolar macrophages and type I IFN in airway homeostasis and immunity. Trends in Immunology 36: 307-314.

16. Wang M, Zhang G, Wang Y, Liu T, Zhang Y, et al. (2015) Crosstalk of mesenchymal stem cells and macrophages promotes cardiac muscle repair. The International Journal of Biochemistry and Cell Biology 58:53-61.
17. Riley KG, Pasek RC, Maulis MF, Dunn JC, Bolus WR, et al. (2015) Macrophages are essential for CTGF-mediated adult $\beta$-cell proliferation after injury. Molecular Metabolism 4: 584-591.

18. Chazaud B (2014) Macrophages: Supportive cells for tissue repair and regeneration. Immunobiology 219: 172-178.

19. Iwalewa EO, McGaw LJ, Naidoo V, Eloff JN (2007) Inflammation: the foundation of diseases and disorders. A review of phytomedicined of South African origin used to treat pain and inflammatory conditions. African Journal of Biotechnology 6: 2868-2885.

20. Libby P (2007) Inflammatory Mechnisms: the Molecular Basis of Inflammation and Disease. Nutrition Reviews.

21. Cole GM, Frautschy SA (2010) Mechanism of action of nonsteroidal antiinflammatory drugs for the prevention of Alzheiimer's disease. CNS and neurological disorders drug targets 9: 140-148.

22. Gleeson M, Bishop NC, Stensel DJ, Lindley MR, Mastana SS, et al. (2011) The anti-inflammatory effects of exercise: mechanisms and implications for the prevention and treatment of disease. Nature Reviews Immunology 11: 607-615.

23. Liu H, Talalay P (2013) Relevance of anti-inflammatory and antioxidant activities of exemestane and synergism with sulforaphane for disease prevention. Proceedings of the National Academy of Sciences 110: 19065-19070.

24. Wallace JL, lanaro A, Flannigan KL, Cirino G (2015) Gaseous mediators in resolution of inflammation. Seminars in Immunology 27: 227-233.

25. Lawrence T (2009) The Nuclear Factoy NF-KB Pathway in Inflammation. Cold Spring Harbor Perspectives in Biology 1: a001651.

26. Wajant $H$, Pfizenmaier K, Scheurich $P$ (2003) Tumor necrosis factor signaling Cell Death and Differentiation 10: 45-65.

27. Bradley JR (2008) TNF-mediated inflammatory disease. The Journal of Pathology 214: 149-160.

28. Esposito E, Cuzzocrea S (2009) TNF-alpha as a therapeutic target in inflammatory diseases, ischemia-reperfusion injury and trauma. Current Medicinal Chemistry 16: 3152-3167.

29. Akdis M, Burgler S, Crameri R, Eiwegger T, Fujita H, et al. (2011) Interleukins from 1 to 37 , and interferon-y: receptors, functions, and roles in diseases. $J$ Allergy Clin Immunol 127: 701-721.

30. Cuneo AA, Autieri MV (2009) Expression and Function of Anti-inflammatory Interleukins: The Other Side of the Vascular Response to Injury. Curr Vasc Pharmacol 7: 267-276.

31. Febbraio MA (2014) Role of interleukins in obesity: implications for metabolic disease. Trends in Endocrinology and Metablosm 25: 312-319.

32. Hayden MS, West AP, Ghosh S (2006) NF-KB and the immune response. Oncogene 25: 6758-6780.

33. Matsui Y, Tomaru U, Miyoshi A, Ito T, Fukaya S, et al. (2014) Overexpression of TNF- $\alpha$ converting enzyme promotes adipose tissue inflammation and fibrosis induced by high fat diet. Experimental and Molecular Pathology 97: 354-358. 